\title{
AUGUSTO MONTERROSO Y LA MINIFICCIÓN, DE LA RUPTURA A LA BANALIZACIÓN
}

\author{
Alejandro Lámbarry \\ Benemérita Universidad Autónoma de Puebla \\ alejandro.lambarry@correo.buap.mx
}

Resumen: Este artículo expone el contexto de creación de "El dinosaurio", cuento de Augusto Monterroso. A mediados del siglo XX el desafío del autor guatemalteco se situaba en la vanguardia formal, de ahí que su búsqueda lo llevara a experimentar con fábulas, géneros misceláneos y la minificción. A finales de su vida, la minificción se convirtió en un género popular y de moda, y él, en uno de sus precursores principales. Analizamos este cambio en la minificción desde la teoría de Bourdieu, específicamente mediante sus conceptos de "desgaste del efecto de ruptura" y "banalización de la obra consagrada".

Palabras clave: minificción, “El dinosaurio”, Bourdieu, Monterroso, archivo.

\section{AUGUSTO MONTERROSO AND THE FLASH FICTION, FROM RUPTURE TO BANALIZATION}

\begin{abstract}
This article analyzes the creative context of Augusto Monterroso's flash fiction "El dinosaurio". Living in the middle of the 20th century, a time of great formal and technical experimentation, Monterroso was drawn to new genders as flash fiction, hybrid genres and a new type of fable. It was then he wrote "El dinosaurio". At the end of his life, however, flash fiction became a trendy and popular literary genre, and Monterroso one of its founders. We study this change-flash fiction as an avant-garde practice to a popular one-, specifically by Pierre Bourdieu's concepts of "erosion of the effect of rupture" and the "banalization" of the acclaimed literary work.
\end{abstract}

Keywords: flash fiction, "El dinosaurio", Bourdieu, Monterroso, personal papers.

DOI: https://doi.org/10.24029/lejana.2022.15.2516

Recibido: el 13 de septiembre de 2021

Aceptado: el 18 de enero de 2022

Publicado: el 25 de febrero de 2022 
El cuento "El dinosaurio" de Augusto Monterroso está presente en casi todas las discusiones sobre el género de la literatura breve o minificción. ${ }^{1}$ En este trabajo nos interesa relatar el recorrido literario de Monterroso desde sus primeras obras en verso hasta la creación de sus primeros tres libros y, en especial, de su cuento "El dinosaurio". Con lo anterior intentamos comprobar que la minificción era, a mediados del siglo XX, una práctica de vanguardia formal y de élites culturales que se convirtió, en el transcurso de ese siglo, en un elemento de gran difusión, producción y consumo. En palabras de Pierre Bourdieu, la minificción aprovechó a mediados del siglo pasado el "desgaste del efecto de ruptura" y la "banalización de las obras consagradas" para convertirse, a finales de ese mismo siglo, en un género con gran capital literario. Bourdieu introduce estos conceptos al tratar en Las reglas del arte de los posicionamientos de "los recién llegados heréticos" (Bourdieu, 2015: 376) en el campo literario. ${ }^{2}$ Para que sus obras y sus posicionamientos obtengan capital literario es necesario, según Bourdieu, que sucedan cambios internos y externos. La revolución en Europa en 1848 es un cambio externo. Al hablar de los cambios internos, refiere lo siguiente:

la divulgación de las normas de percepción y de valoración que esas obras innovadoras tendían a imponer va acompañada de una banalización de esas obras, o, con mayor precisión, de una banalización del efecto de desbanalización que habían podido ejercer. Esta especie de desgaste del efecto de ruptura varía sin duda según los receptores, y particularmente según la antigüedad de su exposición a la obra innovadora y, al mismo tiempo, según su proximidad al crisol de los valores de vanguardia, ya que los consumidores más enterados [...] son naturalmente los más inclinados a experimentar un sentimiento de hastío y a identificar los procedimientos, los trucos, incluso los tics que hicieron la originalidad inicial del movimiento. (2015:377)

El público selecto, elitista o de vanguardia, reconoce y premia las obras que se distinguen del resto. Este mismo público castiga con la indiferencia a las obras que se convierten en un bien común, en uno accesible y popular. Los llamados por Bourdieu "heréticos" tienen mucho que ganar al presentar su obra como distinta, alejada de la norma y la convención de la "ortodoxia estética". No obstante, si logran posicionarse en el campo, si obtienen capital, se vuelven blanco de futuros ataques: un ciclo interminable que mantiene los dos polos del campo activos. La minificción, ejemplificada en este caso con la obra de Augusto Monterroso, se presentó en un inicio como obra de vanguardia, de "recién llegados heréticos". Pero llevaba consigo el "desgaste del efecto de

\footnotetext{
${ }^{1}$ En el presente estudio seguimos la denominación "cuento" a la hora de referirnos a "El dinosaurio", porque en su momento de escritura no existía el término "minificción", tal como hoy denominaríamos el texto en cuestión. Cabe subrayar que, en otras ocasiones, Monterroso incluso le llamó "novela".

${ }^{2}$ Para Bourdieu, el campo social es un "espacio de juegos históricamente constituidos con sus instituciones específicas y sus leyes y funcionamiento propias" (Bourdieu, 2010: 11). En cuanto al campo literario, su libro Las reglas del arte relata la génesis de dicho campo en Francia del siglo XIX y su desarrollo y consolidación en ese siglo. Podríamos resumir la particularidad de este campo en el hecho de que busca ante todo capital literario.

${ }^{3}$ Bourdieu utiliza en constantes ocasiones conceptos religiosos para aclarar sus ideas, como por ejemplo al hablar de las luchas al interior del campo: "los envites de la lucha entre los dominantes y los pretendientes, entre los ortodoxos y los herejes [...] dependen del espacio de las tomas de posición ya efectuadas" (1998: 347), o "La definición más estricta y más restringida del escritor (etc.) [...] es fruto de un larga serie de exclusiones o de excomuniones destinadas a negar la existencia como escritores dignos de este nombre" (331). En este caso, podemos entender el concepto de "heréticos" y de "herejes" relacionado con el de escritores de "vanguardia". Esto mismo es lo que hace Bourdieu en los párrafos que aborda el efecto de ruptura.
} 
ruptura" que lo convertiría a finales del siglo XX en un género consagrado, de gran capital literario, de la "ortodoxia estética" que espera el siguiente movimiento literario que acuse a sus autores de parecer "superados, trasnochados" (Bourdieu, 2015: 376). En el caso de Monterroso este ciclo se ve reflejado - desde la década de los ochenta — con el gran interés del gran público por su cuento "El dinosaurio", y el interés del público selecto y elitista — en este caso sus críticos — por otras facetas de su literatura.

Empecemos con la vida y el contexto social de Augusto Monterroso que nos permitirá, a su vez, entender su inserción gradual en el campo literario latinoamericano. Monterroso fue originario de Honduras, vivió su adolescencia en Guatemala. Después de largas horas de trabajo como contador en una carnicería, al mismo tiempo que gozaba de una educación y cierta distinción familiar, solía acudir a la sala de lectura de la Biblioteca Nacional. La Biblioteca tenía solo clásicos de la literatura occidental. Con el tiempo, Monterroso escribió de manera abiertamente irónica: "La Biblioteca era tan pobre que sólo contaba con libros buenos" (Monterroso, 1998: 115). No es extraño pues que sus primeras publicaciones, a los veinte años, en el periódico El Imparcial y la revista Acento, llevaran como títulos "El hombre de la sonrisa radiante (Escena infernal)", "Los Duques del Recato (Tragedia)" y "El Iluso Genaro", y tuvieran una clara relación intertextual con la novela de Victor Hugo El hombre que ríe, el Otelo de Shakespeare y El Quijote cervantino. Sus lecturas habían sido en su gran mayoría de los autores europeos canónicos y de siglos anteriores al suyo. Su temporalidad estaba lejos de la vanguardia formal. En cuanto al género literario, se trata de pequeños dramas humorísticos y de cuentos breves. Un hecho poco conocido y de nada común en la época es que Monterroso escribía verso rimado (sonetos y silva), inspirado seguramente en los autores del Siglo de Oro español. Instalado ya en la Ciudad de México - a consecuencia de su exilio después de la dictadura de Jorge Ubico_ publicó en la revista América una silva: "Busco sin afán la palabra y la palabra / es antigüedad, / Infiltrándose, corroyendo, abrazando / sutilmente, cruelmente, / Amorosamente inclinando el nombre / de las cosas / Que gimen bajo su peso como un lirio/ bajo el sol" (Poetry). ${ }^{4} \mathrm{Si}$ bien este poema pudo haber interesado a algunos, es claro que Monterroso pronto lo olvidó o ignoró de manera consciente, ya que nunca volvió a publicarse.

Cuando Monterroso llegó a la Ciudad de México, descubrió un centro cultural fuerte y actualizado, con instituciones literarias sólidas como la legendaria Facultad de Filosofía y Letras de Mascarones - a la que Monterroso visitó regularmente y donde conoció a Juan Rulfo, Juan José Arreola y Rosario Castellanos, entre otros-, las librerías Cristal y la de Porrúa, ${ }^{5}$ editoriales de renombre — trabajó en la Editorial Séneca, de los exiliados españoles José Bergamín y José María Gallegos Rocaful - y varias publicaciones periódicas, como la revista América. Esta nueva temporalidad literaria se convirtió a la vez en un anhelo y en un desafío. En una entrevista concedida en 2001, Monterroso comentó al evocar esos años: "Yo estaba aprendiendo a escribir en

\footnotetext{
${ }^{4}$ De aquí en adelante, seguimos el modo de citar que se indica en la página de internet del archivo de Princeton con el subtítulo: Credit this Material. La página de internet se encuentra bajo el nombre de Augusto Monterroso Papers, 19212003, catalog/C1109.

${ }^{5}$ Salvador Novo escribe lo siguiente sobre la librería Porrúa: "Y veamos cómo entran y salen los jóvenes estudiantes que vienen a buscar un libro de texto, o a informarse de si ya llegaron más ejemplares de la traducción del Ulises al español" (Novo, 1996: 195).
} 
poetas de trescientos años antes. Entonces me inhibí de la idea de ponerme al día [...]. Me di cuenta también de que si quería expresar cosas poéticas, podría hacerlo también por medio de mi prosa. Terminé como algunos otros, por no hacer distingo entre prosa y verso, cosa que viene, si no de Baudelaire, de Mallarmé" (Polo García). ${ }^{6}$

Es necesario revisar un hecho importante para entender de manera clara el cambio o, en palabras de Pascale Casanova, la aceleración temporal que vivió Monterroso en la década de los cuarenta en México. ${ }^{7}$ El medio literario mexicano tenía acceso a publicaciones de vanguardia como fue, por ejemplo, la revista Sur. En la biblioteca personal de Monterroso — conservada en su archivo de la Universidad de Oviedo - se cuenta con casi toda la colección de esta revista. Podemos suponer que el autor leyó en su momento las fábulas de James Thurber, y también a Jorge Luis Borges, figuras clave en su obra literaria y, en específico, en el uso de la brevedad. Monterroso fue, de hecho, el primero en publicar un texto sobre Borges en México, lo hizo en el suplemento México en la Cultura del diario Novedades en 1954. Cuando alabó al argentino, se interesó en gran medida en su estilo: Borges renovó el idioma español al usarlo con "claridad y precisión y belleza" (Monterroso, 1991: 54). Para seguir su ejemplo, Monterroso se impuso una escritura pausada y, como veremos después, un proceso de reescritura sumamente laborioso que implicaba una constante edición de sus textos.

En estas mismas fechas en las que leyó a Borges, Monterroso escribió un texto que podríamos ubicar como el pasaje o el puente entre el escritor que imitaba a poetas del Siglo de Oro y el autor de "El dinosaurio". Se trata de un texto inédito, y se titula "Ni escribir un poema":

Ni pensar de algún acto: 'es idiota', porque la humanidad está dividida en sólo dos porciones, a saber: los idiotas y los que no lo son* (* Que son los imbéciles) / Ni gritar, / ni exclamar, / ni proferir, / con gesto de pueril intolerancia: / ‘iDios no existe, sólo es una patraña!' / pues bien podría ser / que Dios realmente no existiera, / o que estuviera muerto / en un bosque, comido por hormigas / y por escarabajos; / o tan sólo dormido como Gulliver / en un país de enanos / en el que la palabra 'patraña' significara 'Dios' / y lo hiciera despertar sobresaltado. ("Ni escribir un poema")

El texto está escrito en verso libre y se encuentra en el pasaje entre un poema y una prosa poética. Monterroso utiliza por primera vez el paratexto de manera creativa: plantea con el título la introducción del poema y sorprende al lector de manera humorística con la cita. A diferencia de sus primeros textos, en los que la referencia se mantenía parcialmente velada, en este nombra de manera explícita la relación intertextual con el Gulliver de Jonathan Swift; como en el caso de Borges, el texto se construye de manera abierta, con los otros textos, en lugar de realizar con ellos

\footnotetext{
${ }^{6}$ Es muy posible que Juan José Arreola, quien pocos años antes había vuelto de una estancia en París, donde trabajó en la Comédie Française, le presentara a estos autores franceses a Monterroso. En todo caso, Monterroso publicó sus primeras plaquettes en las colecciones Los Epígrafes y Los Presentes, dirigidas por el autor jalisciense. Los cuentos de esas publicaciones ("El concierto" y "El eclipse", "Uno de cada tres" y "El centenario") forman parte ya del Monterroso maduro: un autor que conjunta la brevedad con la prosa y un estilo paródico.

${ }^{7}$ Pascale Casanova entiende a la vanguardia como el acto de innovación formal en relación con una temporalidad impuesta desde un centro cultural. A este centro cultural lo definirá en The world republic of letters como: "what might be called the Greenwich meridian of literature makes it possible to estimate the relative aesthetic distance from the center of the world of letters of all those who belong to it. This aesthetic distance is also measured in temporal terms, since the prime meridian determines the present of literary creation, which is to say modernity" (Casanova, 2007: 88).
} 
un guiño intelectual. Y, por último, utiliza dos estilos literarios en clara oposición paródica: el coloquial (los idiotas y los que no lo son [...] Que son los imbéciles) y el lírico (Ni gritar, / ni exclamar, / ni proferir, / con gesto de pueril intolerancia). Monterroso adquiere, de esta manera, distancia con el escritor que fue mediante una concepción más compleja con respecto a lo que rodea y da estructura al texto (paratexto), con las relaciones intertextuales y con el registro complejo y diverso del lenguaje. Es justamente en esta distancia o separación entre uno y otro autor donde ocurre la parodia y el efecto humorístico. Es en esta distancia donde se desarrollará eventualmente su literatura de madurez.

Monterroso tenía treinta y ocho años cuando publicó Obras completas (y otros cuentos). Para entonces ya había publicado buena parte de sus cuentos en revistas especializadas como la Revista de Guatemala, que dirigía Cardoza y Aragón; El Siglo, donde colaboraba Pablo Neruda; e incluso había ganado un premio, el Premio Nacional de Cuento Saker-Ti en 1952. Aun así, tardó dos años — desde que recibió la propuesta de publicación en la editorial de la UNAM — en revisar los cuentos para la versión final de su libro. Tal era la demora que a manera de broma el catedrático español Carlos Bosch, desde la Imprenta Universitaria, le envió una carta en la que se quejaba de que Obras completas (y otros cuentos) había quedado varado en su proceso de publicación por una estrategia de sabotaje de su autor: "Creo que se trata aquí de un nuevo intento de desacreditar a la Universidad y su sistema de distribución por elementos refugiados centroamericanos comunistas e indeseables" (General). Monterroso se preocupó sobremanera por su estilo. La brevedad equivalía, en su aprendizaje, a la poesía y a la literatura de vanguardia, cuyo modelo era Borges.

Las reseñas que se publicaron sobre Obras completas (y otros cuentos) destacaron en un punto central: se trataba de un libro de la vanguardia literaria. De esta manera, en el suplemento $L a$ Cultura en México y en la revista Cuadernos de París se le comparó directamente con Borges. Alí Chumacero alabó en Vida Universitaria que Monterroso fuera de los autores "que mayormente se preocupan por deslucir el lugar común” (Chumacero, 1960: XI). ${ }^{8}$ José Emilio Pacheco lo trató como "el primer filósofo realmente original que haya producido América hispánica" (Pacheco, 1959: 5), y, por último, en The New York Times Book Review escribieron: "Central America can also celebrate the emergence of an accomplished short-story writer in Augusto Monterroso, whose Complete Works and Other Stories is a welcome departure from the indigenous manner" ("Complete Works and Other Stories", 1960). Se trata de una literatura compleja, intelectual incluso; alejada de los temas y estereotipos de la región. Ningún reseñista hizo una mención especial al cuento "El dinosaurio", que se entendió entonces como una parte orgánica del todo, un cuento que no se distinguía en complejidad temática y precisión de estilo del resto. Este hecho es significativo, porque la recepción de la crítica evitó usar etiquetas o motes alusivos a la brevedad. No se habló de una minificción, tampoco de un autor de brevedades. Se destacó, repito, el hecho de que fuera un autor original y a la vez complejo en su búsqueda formal y temática. La suya era, en palabras de Bourdieu, "La acción subversiva de la vanguardia, que desacredita las convenciones vigentes” (Bourdieu, 2015: 376).

\footnotetext{
${ }^{8}$ De aquí en adelante, seguimos el modo de citar anteriormente implantado del archivo de Princeton para las entradas de la colección Augusto Monterroso de la Biblioteca de la Universidad de Oviedo.
} 
Esta búsqueda de la vanguardia formal, que, como hemos visto, pudo iniciarse con su llegada a México, se volvió en el transcurso de los años más intensa. Diez años separan la publicación de Obras completas (1959) de La oveja negra y demás fábulas (1969), su segundo libro. En este tiempo Monterroso se preocupó sobre todo por no repetirse, por evitar escribir un nuevo libro de cuentos; quería ser original, mantener un estilo de escritura único por su precisión. Dos años antes de la publicación de La oveja negra y demás fábulas realizó un viaje a Londres. En dicho viaje escribió en un diario lo siguiente:

Siento que no puedo encontrar la forma de expresión adecuada. En mi interior bulle una cantidad de ideas y sentimientos para expresar con cuales no encuentro una forma. Todas me parecen gastadas, anquilosadas, ridículas o cursis. Pensar que un cuento debe tener nudo y desenlace me horroriza. Las formas demasiado modernas no puedo usarlas puesto que todo el mundo las usa. Decididamente, no encuentro mis expresiones. Soy demasiado perezoso para buscar nuevas, mías. No sé que voy a hacer. Por otra parte, no puedo seguir sin escribir lo que llevo dentro, bueno o malo, poco o mucho, no sé. Quizá la costumbre de escribir todos los días sin forma, como con este cuaderno pienso hacer, ayude algo. (Notebook 1967)

Monterroso cuenta con el tema, pero desea escribir algo nuevo, evitar las formas gastadas y anquilosadas. Para entonces había escrito "El dinosaurio" y escribía fábulas a manera de divertimento. Pero era tanta su obsesión que al final sentimos una suerte de desahogo cuando dice que escribirá en su diario lo que lleva dentro, "bueno o malo". De regreso de ese viaje, el editor Joaquín Díez-Canedo Manteca invitó a Monterroso a publicar en la editorial Joaquín Mortiz. Víctima de la misma inseguridad vivida diez años atrás, Monterroso le envió Obras completas... El editor insistió en que le enviara un texto original, y fue hasta entonces cuando Monterroso puso en consideración el manuscrito que se convertiría en La oveja negra y demás fábulas. La recepción de La oveja negra fue igual o incluso más positiva que la de Obras completas. Elogiaron el texto Isaac Asimov y García Márquez. Ángel Rama escribió en La Opinión Cultural de Buenos Aires que Monterroso se había alejado de "tropicalismo literario" (Rama, 1995: 25), significando con ello que era un autor interesado en la vanguardia literaria más que en los temas que fueron afines e importantes para la época, como la identidad hispanoamericana y el realismo mágico.

En 1972 Monterroso recuperó textos que ya había escrito o publicado a manera de reseñas y ensayos, con otros nuevos, en este caso cuentos, cuentos breves, y textos autobiográficos, en su tercer libro: Movimiento perpetuo. En lugar de publicar un texto misceláneo decidió, sin embargo, darle una estructura sólida utilizando para ello el paratexto y las relaciones intertextuales. Escribió en la introducción: "Hay tres temas: el amor, la muerte y las moscas. Desde que el hombre existe, ese sentimiento, ese temor, esas presencias lo han acompañado siempre. Traten otros los dos primeros. Yo me ocupo de las moscas" (Monterroso, 1991: 11). Luego colocó en todo el libro referencias intertextuales (Luciano, Jaime Sabines, Wittgenstein, Marcial, Chilam Balam, entre muchas otras) alusivas a las moscas que alternan con sus propios textos. También agregó las ilustraciones de moscas que realizó Vicente Gandía. La mosca se convirtió así en la herramienta para convocar a la tradición literaria y, en una suerte de armazón que nos muestra la unión y la correspondencia de todas sus partes, un andamio volátil; y la mosca puede ser también, como dice 
Monterroso en la introducción, el símbolo del Mal, entendido este como personaje o inspiración literaria del libro.

En el epígrafe de Movimiento perpetuo, Monterroso escribe: "La vida no es un ensayo, aunque tratemos muchas cosas; no es un cuento, aunque inventemos muchas cosas; no es un poema, aunque soñemos muchas cosas. El ensayo del cuento del poema de la vida es un movimiento perpetuo; eso es, un movimiento perpetuo" (1991: 8). Su interés se enfoca en la posibilidad de un libro híbrido con diversos géneros literarios; no se refiere a la brevedad o a la minificción como un nuevo género. Esto a pesar de que en el libro hay un texto de una sola frase, "Fecundidad"; otro de dos frases y diez textos con la extensión de un párrafo. La crítica tampoco destacó en ese momento la minificción como un nuevo género literario, más bien lo entendió como la muestra de un estilo depurado. Así lo afirma, por ejemplo, Efraín Huerta: "Una vez más este buen caballero don Augusto Monterroso me ha deslumbrado con su prosa suave, gentil, criolla" (Huerta, 1985: 11).

De esta manera, para Monterroso, la brevedad era un medio, no un fin, que le permitía lograr un estilo con "claridad y precisión y belleza" (Monterroso, 1991: 54). Además, mencionó en varias presentaciones del libro que no escribía, sino que editaba. Esto, que se entendió como una boutade, no lo era del todo. Ya hemos visto el tiempo que le tomó corregir cuentos que ya había publicado en revistas especializadas, con el fin de publicar su primer libro. Diez años pasaron para que publicara La oveja negra, que no alcanzaba las cien páginas. Es posible que hayan transcurrido treinta años desde los primeros borradores de su novela Lo demás es silencio, hasta su publicación final. ${ }^{9}$ El estilo era para él sumamente importante, de manera similar a lo que — según Bourdieu — representaba para Baudelaire y Flaubert:

Convertir la escritura en una investigación inseparablemente formal y material dedicada a tratar de inscribir en las palabras más eficaces para evocarla, por su forma misma, la experiencia intensificada de lo real que han contribuido a producir en la mente misma del escritor, es obligar al lector a detenerse en la forma sensible del texto, material visible y sonoro, lleno de correspondencias con lo real que se sitúan a la vez en el orden del sentido y en el orden de lo sensible. (Bourdieu, 2015: 169)

Bourdieu ubica la génesis del campo literario francés en el momento en que estos dos autores, Baudelaire y Flaubert, dedicaron su vida a la búsqueda de un lenguaje artístico en vez de la búsqueda de una trama sorpresiva o de crítica social. Su escritura privilegia el arte por el arte; y es consumida por algunos pocos, aquellos que conocen la tradición literaria y la manera en que Baudelaire y Flaubert la renuevan. De igual manera, a Monterroso no le interesaban las modas y las etiquetas de su época, no escribía una literatura con una agenda política o social; tampoco escribía novelas, que era el género más popular del momento. Ángel Rama escribió en una reseña sobre Monterroso, de 1974, que "Por ese humor y ese laconismo, inusuales en la selva retórica latinoamericana, por varios cuentos perspicaces acerca de la vida intelectual, por una reposada manera de desinflar el alborozo colonialista, Augusto Monterroso conquistó al más diminuto club

\footnotetext{
${ }^{9}$ En 1952 escribió borradores de una novela biográfica sobre un contador humanista, Evaristo, de un gran parecido con Eduardo Torres. Si el libro finalmente se publicó en 1978, entonces pasaron casi treinta años desde los primeros borradores hasta la versión final.
} 
de fans del continente" (Rama, 1995: 24). Aquí la mención a un club "diminuto de fans" se entiende como un elogio. Monterroso tiene un compromiso con la tradición literaria y no con la fama, la popularidad o el éxito comercial. Por tal motivo llevará a cabo una de sus mayores revoluciones: renovará dicha tradición como autor guatemalteco, es decir, de la periferia. ${ }^{10}$

Retomando a Bourdieu, el público selecto es aquel que identifica la originalidad de una obra y le otorga por eso un gran valor inicial, que, al transcurrir del tiempo, si esa originalidad se populariza, se pierde. ${ }^{11}$ Cuando todos escriben como Borges, el "efecto de ruptura" irá para el autor o la autora que revienten este estilo. Cuando la literatura de la brevedad se convierte en moda, habrá caído en el "desgaste del efecto de ruptura" o en la "banalización de la obra consagrada". En el momento en que Rama escribe su reseña, Monterroso es un autor selecto, difícil por la complejidad de su estructura y sus propuestas de literatura breve. Al igual que Baudelaire y Flaubert, es un escritor que busca ante todo innovar y lograr la precisión, la claridad y la belleza en el lenguaje que siempre apreció. Esto cambiará a principios de la década de los setenta.

En 1973 Monterroso decide contratar a Carmen Balcells como su agente literaria. A pesar de que su relación de trabajo dura apenas algunos años, toda la obra de Monterroso se publicará en España en esa década. En la terminología de Rama, Monterroso dejó las pequeñas empresas culturales (la editorial universitaria, Joaquín Mortiz) y dio el salto a los grandes consorcios (Alianza o Seix Barral). Otro hecho significativo - y que está relacionado con el primero- es que sus tiempos de publicación cambiaron. A diferencia de sus primeros tres libros (Obras completas, La oveja negra y Movimiento perpetuo), publicados entre 1959 y 1972, publicó cuatro libros en el transcurso de seis años. Inició entonces la divulgación masiva y la popularización de su obra. En 1982 la revista española Quimera responde a este fenómeno con la publicación de un artículo que propone un boom alternativo. Además de los autores que han obtenido renombre internacional, y cuya obra no necesita mayor publicidad, la revista propone otro grupo a cuyos miembros describe como de "estructura aparentemente cerrada" ("La gran narrativa americana"). En este grupo se encuentran Borges, Clarice Lispector, Guimarães Rosa y Monterroso. Si para Borges la definición de estructura aparentemente cerrada podría hacer alusión a sus prácticas metaficcionales, en Guimarães Rosa aludiría al uso libre indirecto y el monólogo interior. Pero con Monterroso la

\footnotetext{
${ }^{10}$ Es esto mismo lo que afirma Gloria González Zenteno: "Numerosos escritores latinoamericanos han emprendido una aventura de liberación ideológica respecto de hegemonías culturales. Las metrópolis con que se enfrentan son imposibles de situar con precisión, porque no se limitan a una simple exterioridad geográfica, como se pensaría de Estados Unidos, París o Madrid. Esos centros culturales ciñen las culturas latinoamericanas en forma ideológica, cultural, económica o política con determinados cánones formales, temáticos y de perspectiva a través de ciertas expectativas de lectura. Es ante esto que la voz del escritor monterrosiano aprovecha la oportunidad de pronunciarse. La sensación de impotencia e inseguridad que sus textos provocan en la lectura es un saludable efecto de este cuestionamiento, a la vez que condición inicial para la transformación de la realidad discursiva" (Zenteno, 2004: 61). ${ }^{11}$ Bourdieu explica este mismo fenómeno fuera del campo literario con el ejemplo de los perfumes: "Del mismo modo que las grandes marcas de perfumes que han dejado que su clientela se extendiera demasiado han ido perdiendo una parte de sus primeros clientes a medida que iban conquistando públicos nuevos... del mismo modo, debido a que las diferencias en materia de capital económico y cultural se retraducen en desfases temporales en el acceso a los bienes excepcionales, un producto hasta entonces altamente distintivo que se divulga, por lo tanto se desclasa" (Bourdieu, 2015: 379).
} 
etiqueta estaría ligada a la inestabilidad genérica de sus textos, en específico, a la creación de la minificción.

En 1969, El Cuento. Revista de Imaginación creó el concurso de Cuento Brevísimo, con un gran éxito y una primera consolidación institucional, ya que se dio con una revista de gran trayectoria e importancia en México. En la década de los setenta surgieron las primeras antologías de cuentos en los que se incluyó "El dinosaurio". La primera, editada por Mario Rodríguez Fernández y publicada en Santiago de Chile (1972), incluyó de Monterroso "El dinosaurio" y “Míster Taylor". Después, en 1973 y 1974, tenemos las antologías Zoo en cuarta dimensión y El libro de la imaginación, donde el interés se enfoca en la literatura breve con temática ya sea animal o fantástica. ${ }^{12}$ Por último, el año clave de este proceso de consolidación de Monterroso como el creador de algo nuevo y sumamente importante fue 1993, cuando Italo Calvino mencionó en sus famosas cátedras en la Universidad de Harvard a "El dinosaurio" como el cuento del futuro: "Me gustaría preparar una colección de relatos que consistieran en una única oración o incluso de una sola línea. Pero hasta ahora no he encontrado ninguna comparable a la del escritor guatemalteco Augusto Monterroso: «Cuando despertó, el dinosaurio todavía estaba allí»»"(Calvino, 1993: 51).

Después de Calvino, la popularidad fue tanta que, en 2000, el Diccionario Larousse compró el derecho de publicación de "El dinosaurio" para el cuaderno de ejercicios de su libro de español, de nivel secundaria. En ese mismo año, la antología Relatos vertiginosos, compilada por Lauro Zavala, fue de las primeras que se interesaron únicamente en el género de la minificción. Y en el centro de ese nuevo canon estaba, claro, Monterroso. Desde entonces su importancia y reconocimiento crecieron en dimensiones jurásicas. Dos años después de esa antología, Lauro Zavala dedicó una edición crítica de 135 páginas a un cuento que tiene siete palabras. Al morir Monterroso, en la sección de Cultura del periódico Reforma (México) apareció la caricatura de un dinosaurio llorando y Monterroso con paraguas y libro debajo. El artículo de La Jornada llevaba como título: "Despiden al maestro del relato corto". Al mes siguiente, en un número de Babelia, suplemento cultural del diario El País (España), varios escritores, entre ellos, Juan Villoro, Marcos Giralt Torrente e Ignacio Padilla, reescribieron distintas versiones de "El dinosaurio".

La minificción se convirtió a finales del siglo XX en una marca o etiqueta con la que pudo popularizarse a un autor que décadas atrás, según Ángel Rama, tenía "al más diminuto club de fans del continente" (Rama, 1995: 24). Una obra que se calificó de filosófica, de estructura cerrada y de vanguardia (en relación con Borges) se resumió, al final de la vida de su autor, en un cuento de una sola frase y un nuevo género de gran difusión. Tenemos aquí — según Bourdieu- el ascenso de "los recién llegados heréticos" a la "ortodoxia estética". "El dinosaurio" tuvo primero a un público especializado y hasta esnob, que pudo haberlo leído con una sonrisa cómplice, similar a la respuesta de un espectador ante la obra de Marcel Duchamp. Juan Villoro resumió esta postura cuando escribió sobre "El dinosaurio": "la creación deriva de la crítica, de la insumisa relectura" (Villoro, 2001: 28). A finales de la vida de Monterroso, su público lector se amplió a otro que conocía y hasta podía recitar y reescribir el cuento en cualquier contexto (es famoso el contexto político

\footnotetext{
${ }^{12}$ Quiero agradecer por su ayuda en la investigación de la minificción en las décadas de los sesenta y setenta a Fernando Sánchez Clelo.
} 
mexicano, donde el dinosaurio hace referencia a los políticos priistas, sobre todo de la vieja guardia). Monterroso tuvo una lista interminable de seguidores que adoptaron la nueva forma que a la crítica de su momento le pareció simplemente una forma más de lo que ya escribía. Cuando recibió el premio Príncipe de Asturias en 2000 supo identificar los motivos por los cuales se le premiaba; en sus notas personales para redactar su discurso escribió: "Seguramente no quiero, ni me (vendría) bien, convertirme, o presentarme como un propagandista de ultranza del cuento. Pero mucho he oído o leído en estos días en el sentido de que, en mí, en cierta forma, se ha premiado este género. Y de ser así, ¿qué cosa mejor? ¡Que se premie el cuento, el ensayo y la brevedad!” (Notebook).

Frente a la "ortodoxia estética" surgió, no obstante, el "desgaste del efecto de ruptura". A la consagración de Monterroso como un pionero del nuevo género de la minificción se contrapone la lectura selecta y elitista — en términos de Bourdieu — de sus críticos, quienes dejaron de lado este cuento y se dedicaron, en cambio, al estudio de otras obras. El primer estudio ambicioso sobre Monterroso fue el de Wilfrido Corral: Lector, sociedad y género en Augusto Monterroso. Corral abordó en su libro Obras completas, La oveja negra y Movimiento perpetuo a partir de la teoría de la recepción y la noción de género literario de Todorov. Francisca Noguerol en La trampa en la sonrisa: sátira en la narrativa de Augusto Monterroso realizó, por su parte, un estudio minucioso del uso del humor, la sátira y la parodia en sus cuentos completos y, en especial, en la novela $L o$ demás es silencio. En Monterroso en sus tierras: espacio e intertexto An Van Hecke se enfocó en el tema del espacio y el intertexto. Con ellos en mente, descubrió 2652 referencias intertextuales a 1167 autores en la obra completa de Monterroso. Los espacios en los que se desarrolló su obra fueron literarios - la capilla Alfonsina, la UNAM, congresos literarios, librerías-y selváticos. Ninguno de estos académicos dedicó un capítulo ni mención especial a "El dinosaurio", ninguno estudió el género de la minificción. La única académica que ha abordado hasta ahora el cuento de "El dinosaurio" es Gloria González Zenteno en su libro El dinosaurio sigue allí: arte y política en Monterroso. Pero Zenteno estudió el cuento desde su subversión formal y su impacto políticocultural, más que como minificción.

Es decir que, ante el aluvión mediático y la subsiguiente fama de Monterroso, como uno de los pioneros de un nuevo género literario que cuenta ahora con gran difusión y reconocimiento, los lectores críticos y académicos optaron por enfocar su atención en otros aspectos de una obra compleja y diversa (Monterroso escribió novela, diario, autobiografía, ensayo, cuento, fábula). Ante el "desgaste del efecto de ruptura" y la "banalización de la obra consagrada", estos lectores especializados destacaron otros textos que preservan todavía un aire de vanguardia, de únicos, de especiales. El genio de Monterroso es que su literatura da para ambos grupos; sigue siendo un "hereje" para sus lectores especializados y un autor ubicado en la "ortodoxia estética" para sus lectores hedonistas. 


\section{Bibliografía}

BOURDIEU, Pierre (2010): El sentido social del gusto. Elementos para una sociología de la cultura. México, Siglo XXI Editores.

--- (2015): Las reglas del arte. Génesis y estructura del campo literario. Barcelona, Editorial Anagrama.

Calvino, Italo (1993): Six Memos for the Next Millennium. Cambridge, Vintage International.

Casanova, Pascale (2007): The World Republic of Letters. Cambridge, Harvard University Press.

CORRAL, Wilfrido (1985): Lector, sociedad y género en Augusto Monterroso. México, Centro de Investigaciones Lingüístico-Literarias, Instituto de Investigaciones Humanísticas, Universidad Veracruzana.

GONZÁlez ZENTENO, Gloria Estela (2004): Arte y política en Monterroso. El dinosaurio sigue allí. México, Editorial Taurus_-Universidad Nacional Autónoma de México, 2004.

Monterroso, Augusto (1971): Obras completas (y otros cuentos). México, Joaquín Mortiz.

--- (1991): Movimiento perpetuo. México, ERA.

--- (1998): La vaca. México, Alfaguara.

--- (2012): La oveja negra y demás fábulas. México, ERA.

Noguerol JimÉNEZ, Francisca (1995): La trampa en la sonrisa: sátira en la narrativa de Augusto Monterroso. Sevilla, Universidad de Sevilla.

Novo, Salvador (1996): Viajes y ensayos I. México, Fondo de Cultura Económica.

SÁNCHEZ Clelo, Fernando (2020): La composición de la minificción contemporánea. Tesis doctoral. Puebla, Benemérita Universidad Autónoma de Puebla.

RAMA, Ángel (1995): “Un fabulista para nuestro tiempo". En Wilfrido H. Corral (ed.): Refracción: Augusto Monterroso ante la crítica. México, Universidad Nacional Autónoma de México: 24-29.

--- (2005): “El boom en perspectiva”. Signos Literarios, 1: 161-208.

VAn Hecke, An (2010): Monterroso en sus tierras: espacio e intertexto. Xalapa, Instituto de Investigaciones Lingüístico-Literarias, Universidad Veracruzana.

VILLORO, Juan (2001): “El jardín razonado”. En Efectos personales. México, ERA: 28-37.

Zavala, Lauro (2002): El dinosaurio anotado. Edición crítica de "El dinosaurio" de Augusto Monterroso. México, Alfaguara.

\section{Augusto Monterroso Papers, 1921-2003. Archivo de la Universidad de Princeton}

General Bo-Bu, 1959-2002, Augusto Monterroso Papers, Box 22, Folder 2; Manuscripts Division, Department of Rare Books and Special Collections, Princeton University Library.

Ni ESCRIBIR UN POEMA; Augusto Monterroso Papers, Box 17, Folder 34; Manuscripts Division, Department of Rare Books and Special Collections, Princeton University Library. 
NoteBook, 1967, Augusto Monterroso Papers, Box 1; Manuscripts Division, Department of Rare Books and Special Collections, Princeton University Library.

NoteBooK, undated, Augusto Monterroso Papers, Box 2; Manuscripts Division, Department of Rare Books and Special Collections, Princeton University Library.

PoETRY; Augusto Monterroso Papers, C1109, Manuscripts Division, Department of Special Collections, Princeton University Library.

Polo GarCía, Victorino; Augusto Monterroso Papers, C1109, Manuscripts Division, Department of Special Collections, Princeton University Library.

\section{Colección Augusto Monterroso, Biblioteca de la Universidad de Oviedo}

COMPLETE WORKS AND OTHER STORIES; Colección Augusto Monterroso, The New York Times Book Review, 1960, Biblioteca de la Universidad de Oviedo.

Chumacero, Alí; Colección Augusto Monterroso, Vida Universitaria, 1960, Biblioteca de la Universidad de Oviedo.

HuERTA, Efraín; Colección Augusto Monterroso, "Libros y antilibros", El Gallo Ilustrado, 1985, Biblioteca de la Universidad de Oviedo.

La gran nARRATIVA AmERICANA; Colección Augusto Monterroso, Quimera. Revista de Literatura 1982/15, Biblioteca de la Universidad de Oviedo.

PACHECO, José Emilio; Colección Augusto Monterroso, "Obras completas (y otros cuentos)", reseña, México en la Cultura, 1959, Biblioteca de la Universidad de Oviedo.

(C) Alejandro Lámbarry

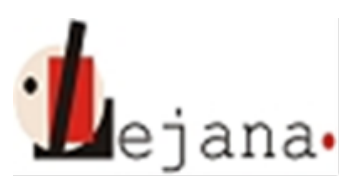

http://ojs.elte.hu/index.php/lejana

Universidad Eötvös Loránd, Departamento de Estudios Hispánicos

1088 Budapest, Múzeum krt. 4/C 